\title{
The Local Unversities' Transitional Development and "Five 'One' Project" Construction Plan
}

\author{
Naizhu Huang, Xiaoping Wang, Jiaming Zhong * \\ Xiangnan University ,Chenzhou 423000,Hunan \\ jmzhongen@163.com \\ * Corresponding Author
}

\begin{abstract}
Xiangnan University put forward "Five 'One'project" construction plan in the implementation of the Ministry of education "Guidance on carrying out guiding some undergraduate colleges to transform and develop the university of applied technology in the pilot reform" . In "Five 'One' project" implementation construction plan, Xiangnan University has drawn up and implemented "Xiangnan University school(department) secondary management system reform" ,The management approach of integration of production and education, school and enterprise(local) cooperation in Xiangnan University" and "Management approach of "double-qualified" talents introduction and training of Xiangnan University" . All these measures enable it to become a pilot local university of the transitional development of Hunan province and an allied member of the China Application Technology University (College) .It has made gratifying achievements on the road of transitional development of local colleges and universities.
\end{abstract}

Keywords-Local colleges and universities; transitional; development; "Five 'One' project" construction.

\section{INTRODUCTION}

Xiangnan University which is an ordinary undergraduate college ,located in Hunan province. It is mainly dependent on provincial fiscal support and bears the responsibility for provincial, city and county business unit, industry(enterprises) to develop talents and provide service. Since upgraded to undergraduate in 2003, due to the traditional academic college personnel training mode, its graduates fall behind the traditional undergraduate colleges and universities both in academic research ability and practice ability. The graduates employment is without comparative advantage and local characteristics. With the industry transformation and upgrading and the structure adjustment of higher education, the schooling thought of transforming to application technology university in order to meet the need of national economic and social development to cultivate applied talents not only conforms to" the national medium and long-term education reform and development plan outline (2010-2020) "spirit, but also conforms to the actual needs of local colleges and universities serve economic and social development .School transformation development needs to carry on the demand transmission reform in aspects of school system, professional construction, curriculum, training mode, teachers structure, management mode and so on , to break through the traditional academic talents training mode and build a applied talents training mode.As a result, under the correct leadership of the school party committee, after extensive research and fully take the schooling experience of applied universities at home and abroad ,Xiangnan University put forward and practices "Five 'One' project" to speed up the transformation of school development for application technology university.

\section{THE BASIC CONNOTATION OF XIANGNAN}

\section{UNIVERSITY "FIVE 'ONE' PROJECT" CONSTRUCTION}

On February 26, 2014, prime minister Li Keqiang held a state council executive meeting to deploy speeding up the development of modern vocational education and requested "to establish credits accumulation and transformation system, break through the rising channel from secondary vocational school, junior college, undergraduate to graduate student and lead the transformation of a group of ordinary undergraduate colleges and universities to the application technology colleges ." Subsequently, the Ministry of education carried out Guidance on carrying out guiding the pilot reform of the transformation and development to application technology colleges of some undergraduate colleges and universities transformation (draft), which provides the policy basis for local colleges and universities to transitional reform.In general, the university of applied technology has the following characteristics: "serve the industry or the local regional economic and social development; applied talents cultivation as the goal of talent training; take emerging curriculum or new direction of professional training as the main body as curriculum settings; take facing application as guiding principles of curriculum construction; take building the system of applied science and developing applied scientific research as the guiding ideology of discipline construction; curriculum system design emphasizes both disciplines and applications and the relationship between these two systems is construction and applied cultivation, not dependent relationship;disciplinary teaching method combined with applied teaching methods; teaching staff have application ability ;industry-university-research is the fundamental way to cultivate applied talents; taking the internationalization path is the important measure to speed up the construction of an applied 
university".[1] School decisively puts forward "Five 'One' project" construction to promote the development of school transformation on the basis of a full research on features of university of applied technology and in combination with the practical and development orientation of school running.

The "Five 'One' project" construction refers to the construction required all the teaching schools(departments) to concentrate and complete in three to five years since 2013. It's studied and decided by school party-government meeting on the basis of suggestions from teaching staff and sufficient demonstration of experts, with the goal to transform from traditional undergraduate colleges and universities to application technology university. One good curriculum: it requires the teaching schools(departments) to do well in at least one or more pilot curriculum which can fully match the enterprise(industry). The pilot curriculum substantial cooperation agreement between colleges and enterprises covers $100 \%$, initial pilot professional employment rate reaches more than $90 \%$ and professional counterpart employment rate is over $80 \%$; One good platform: it requires each teaching school (department) to build a substantial industry-university-research platform. To ensure the cooperation between enterprises, schools, research institutions and the user interaction, display their respective advantages, form a powerful talent education overpass ,combining education services, scientific research, product development and production in integration and improve ability of economy and social development in local university service region; A good textbook: it requires each teaching school (department) to compile more than one core professional materials according to applied talents training standards and their own teaching experience ;One good subject: it requires each teaching school (department) to apply and study at least one university-industry subject according to their fusion spirit. The topic can be a major subject of industry-university-research, new subject which has a big influence to regional industry transformation and can directly bring outstanding economic benefits, the subject which can apply for patent joint development and collaborative innovation or but also talent cultivation experiment (training), practice base construction project; One good team: it requires each teaching school (department) to build "double qualified" teachers with solid theoretical foundation and practice ability,have good cultural literacy and good professional quality.

\section{THE THEORETICAL BASIS OF XIANGNAN}

\section{UNIVERSITY "FIVE 'ONE' PROJECT"}

The proposal and implementation of "Five 'One' project" not only promotes the transformation of school development, but also promote the comprehensive school education reform process. The "Five 'One' project" construction not only conforms to the practice of Marxism but also conforms to the law of higher education teaching.It is a scientific decision-making powerfully boost the sustainable development of the school.

\section{A. Practice view of Marxist}

Practice is the most basic point of Marxist philosophy. Marx had explicitly pointed out: "Philosophers just interpret the world in different ways , but the problem lies in changing the world".Marxist practice view points out that practice is the source of knowledge, the power of knowledge development and standard to inspect the truth of knowledge. Lenin pointed out in Materialism and experience criticism that the view of life and practice should be the primary and basic point of view of epistemology"[2] and Mao Zedong emphasized the practice view of "Seek truth from facts, combine theory with practice and make a survey to the society" [5]in Reform our study. Marxist practice view provides us with a practical way of thinking, namely practice comes first. Take practice as the criterion to study new situations and solve new problems.Don't set out from the transcendental nature or abstract principles to correct the real life, but to seek ideas from reality itself. School transitional development implements the "Five 'One' project" construction fully embodies the application of Marxist practice view in higher education. No matter it's new curriculum setting, industry-university-research platform construction, university-enterprise cooperation research, school-based teaching material development or construction of "double qualified "teachers, we must learn thoughts and wisdom through social practice and market demand ; can never make decisions by imagination and subjective assume .

\section{B. Higher education theory}

As a university cultivating high-level applied talents required by national economic and social development, local university should follow the law of higher education, centering on applied talents cultivation, focusing on teaching, increasing teaching infrastructure construction, implementing the project of prospecting school by talents, deepening teaching reform and effectively improving the quality of applied talents training. The implementation of "Five 'One' project"fully embodies the higher education law of taking teaching as the center of cultivating applied talents of higher education. School teaching centers mainly into four aspects:First, teaching funds investment increases year by year. It's mainly used for infrastructure construction, teaching instruments and equipment purchase and students' experiment \& internship funds; Second, the teaching consciousness of management services is constantly enhanced, aiming at establishing modern university management system, continuously deepening reform of teaching management system and making management better serve the teaching work. Third,research effectively promotes teaching. Teachers improve the academic level and teaching level and form the mutual promotion situation of scientific research and teaching by expanding knowledge through scientific research;Fourth, the principal position of teachers becomes increasingly prominent. School centers on the concept of "When teaching, teachers are dominant and when learning, students are dominant." to carry out the teaching work. Teachers obtain priority in 
aspects of appraisal, studying abroad, pursuing a degree and earning benefits and have strong entrepreneurial mindset.The"Five 'One' project" school strongly launched is essentially an effective measure to implement the center status of teaching.

\section{Countermeasures RESEARCH OF "Five 'ONE'}

\section{PROJECT" CONSTRUCTION IN XIANGNAN UNIVERSITY}

\section{A. Boost university and college (department) secondary management reform in order}

The "Five 'One' project" implemented by university requires to boost university and college (department) secondary management reform in order. University and college (department) secondary management reform reflects the integration thoughts of decentralized management and centralized management in modern management. The traditional centralized management is rooted in the feudal hierarchy which demands unquestioning obedience to superior orders and command and subordinates undertake relatively less responsibility and risk. This management mode can't really play subordinates' enthusiasm and initiative, leading to declined performance and failure to reach organizational goals. The decentralized management is also called "the separation of powers under control". It is a management mode with power separation as the dominant and power centralization supplemented. Its core is to reduce the management center, decentralize management power, truly establish a set of operation mechanism of macroscopic readjustment \& control and college(department) self-running school, expand the autonomy of college(department), greatly arouse the enthusiasm of college(department) of running a school, enhance the responsibility of departments, better play the role of the departments in school development and fully activate vitality of different organizations.Its essence is the resources devolution, namely a new integration and optimization of school power and resource allocation.By changing the management function of the school authority department, setting up the college-centered management system, defining the responsibility and authority of colleges and departments, it improves school efficiency and operation level.Of course, local colleges and universities in order to boost university and college ( department) secondary management reform first require to formulate school policy and solidify their own responsibility and rights of university and college (department);Second, carefully select school (department) managers and bold promote those who are loyal to the school, have work responsibility, execution, management ability and the team cooperation spirits to the school (department) management and fully decentralization; Finally, establish administrator performance assessment and tenure system and form the mechanism of evolution.

\section{B. Formulate "Management approach of integration}

of production and education, school and

enterprise(local) cooperation "ASAP

In order to implement the "Five 'One' project" construction, it need formulate "Management approach of integration of production and education, school and enterprise(local) cooperation " ASAP. The "Management approach of integration of production and education, school and enterprise(local) cooperation " shall fully reflect what Minister Yuan Guiren advocated "Turn schooling ideas really to serving local economic and social development, to the integration between production and education, to train applied and technical talents and to enhancing students' employment entrepreneurship".The "Management approach of integration of production and education, school and enterprise(local) cooperation " should be in accordance with the thought of "profession training docking industry, actual training entering basis, scientific research combines with production, project promotes innovation" , greatly strengthen the close cooperation between

school-enterprise ,school-basis ,school-institute ,take school as basis ,college(department)as main body and extensively carry on the substantial seamless docking with social industry(enterprise).Under the guidance of "Cooperative cooperation, complementary advantages and mutual benefit" ,it innovates talents training mode ,construct" double-qualified "teaching staff, co-construct characteristic specialty with cooperation, co-instruct internship(training) basis and the cooperatively research projects and so on. These enable school and industry(enterprise) joint and share in aspects of talents, resources, project and information ,forming close cooperation relations of comprehensive, multilevel and compact.

\section{Speeding up formulating "Management approach of 'double-qualified' talents introduction and training "}

In order to implement the "Five 'One' project" construction, school need to speed up formulating "Management approach of 'double-qualified' talents introduction and training " .'double-qualified' talents refers to those talents have both a solid basic theoretical knowledge and high teaching level and certain scientific research ability, but also have actual working experience related to the professional industry (enterprise).Local colleges and universities should be in line with the principle of "respect talents, cooperative cooperation, mutual benefit, management by law and common development", strive to build a "double-qualified " teaching group of enough number, reasonable structure and high quality : First , create favorable conditions to speed up the introduction of professional high-level leading talents in urgent need by applied professional and professionals; Second, positively hire senior engineering and technical personnel and management personnel with theoretical knowledge and rich practice experience for part-time teachers, under the principle of 
"Not for all but for the function" ; Third, actively send professional teachers to industry(enterprise) with the principle of "university-enterprise cooperation, mutual benefit ". By means of pre-job and on-the-job training, deep investigation, study in factory ,participating in project research to improve teachers' practical ability and innovation ability and promote the deep combination of the theory and practice; Fourth, actively invest capital to construct university-enterprise cooperation base participate the research and construction of local science and technology industrial, to ensure the completion of the practice goal professional teachers and scientific research achievements transformation; Fifth, improve the"double-qualified" teachers cognizance and management measures and set up the mechanism in favor of "double-qualified" teachers' position and title promotion.

\section{THE PRACTICAL EFFECT OF "FIVE 'ONE'PROJEC"T}

\section{CONSTRUCTION OF XIANGNAN UNIVERSITY}

\section{A. Closely docking industry, specializing in the structural adjustment of success}

School complies with the thought of "professional group of docking industry chain serving local economy, with characteristic discipline docking location advantage to promote local industry development" ideas, takes the initiative to adjust the profession structure, sets up training, constantly improves the matching degree of profession structure and local industry structure.Currently, according to the requirement of Chenzhou overall economic and social development , school takes the initiative to withdraw the majors such as information management and information system and applied physics with low acceptance rate and employment rate .Set up applied chemistry,considering Chenzhou billions of nonferrous metal finishing industry (metallurgy direction); Set up communication engineering, electronic information science and technology, electrical engineering and its automation, considering the electronic information industry cluster formation brought by Hunan video industry base construction;Set up network engineering, computer science and technology considering Chenzhou, supports and develops software and information service industry; Set up biotechnology, international economy and trade, financial management, logistics management, considering Chenzhou strives to develop the five "billions industry" including grain and oil, tobacco, livestock and poultry aquaculture, bamboo and fruit tea; Set up geriatric rehabilitation and nursing, medical imaging technology, clinical medical professional considering the large demand of medical service in Chenzhou.

\section{B. Adhere to the school concept of " integration of production and education, school and enterprise cooperation", industry-university-research education mode popularization}

The industry-university-research education mode is an important approach to cultivate high quality applied innovative talents. Under the guidance of "integration of production and education, school and enterprise cooperation" , school implements "Five 'One' project" , creates the real education environment "Industry-school cooperation, alternation of working with learning " and construct the industry-university-research education mode of "cooperative education, cooperative schooling and cooperative innovation" .

\section{1) School-enterprise cooperative professional}

Cooperative profession refers to each pilot profession on the basis of insisting on industry-university-research cooperation education mode, signs " $3+1$ " mode with well-known enterprises to cultivate applied talents. All the students enter the cooperative enterprises to participate in 1 year's training after three years' study at school. In this way can students make theoretical study deeply integrated with the enterprise practice. Students will directly work in enterprise after graduation.In recently years, school signed cooperation agreement with five famous enterprises both in and out of Hunan province to implement "customized" applied talents training. For example, Institute of economics and management joint with Changsha Flight Attendant Human Resources co., LTD.to set up "flight attendant" class to cultivate flight attendants;Institute of electronic information and electrical engineering joint Hualei Optoelectric co., LTD. to set up" Hualei optoelectric class" to cultivate electronic information professionals; Institute of software and communication engineering joint Shanghai financial valley to set up "IoT financial class" to jointly develop IoT financial professionals;School of physical education joint Hunan Green Island Scenery Ecological Sports co.,LTD to jointly open "golf class" to jointly cultivate specialized personnel to operate and manage golf;Nursing department joint Xiangya hospital to hold"Xiangya class" cultivating nursing talents.

2) School and enterprise cooperative constructing base

School and enterprise cooperative constructs base refers to school cooperate with industry (enterprise) in accordance with "Management approach of integration of production and education , school and enterprise(local) cooperation " to construct a multi-level, multi-dimensional, integrated practice teaching system, including laboratory (training), internship base, innovative entrepreneurial base and research base.For example,besides 21 medical experimental buildings, 1 affiliated hospital , 3 non-affiliated hospitals and 5 teaching hospitals, the medical majors of school also signed an agreement with 53 hospitals to become school internship (training) base; In addition to medical majors, school cooperates with local enterprises and schools to construct 72 internship(training) bases, including 22 education internship bases , 50 major internship(training) 
bases and 11 internship(training) bases earned the title of "Hunan excellent internship(training) bases" .Laboratories are: Institute of electronic information and electrical engineering set up "Xiangnan college-Gospell microwave communication laboratory" with Gospell Co.Ltd. In recent years the research team of this laboratory successfully declared 3 national, provincial science\&technology fund, provincial science\&technology plan project ,6 national patent for utility models.In May 2014, it was awarded the fourth batch" university of science and technology innovation team" in Hunan province; The department of chemistry and life sciences cooperated with Chenzhou Jinwang co., LTD and Chenzhou Jingui Nonferrous Metals (group) co., LTD and set up "Xiangnan rare metals compound and its application" laboratory. In 2011 it was awarded key laboratory of Hunan province; Institute of software and communication engineering cooperate with Changsha Blue Fox Network Co.,Ltd to set up"Network and communication security laboratory" and so on. At present ,school has reclaimed 53 street stores in the implementation of the national "public entrepreneurship, peoples innovation" activities ,preparing to build "college students innovation pioneer park".It becomes a college students' innovation and entrepreneurship practice base.Scientific research bases are: regional economic research institutes, microwave electronic technology research institute, the earth environmental protection research institute, Nanling medicinal resources research institute, institute of preventive medicine research, institute of regional culture, institute of computer application technology and other scientific research bases. They are all built by relevant departments with local enterprises \& research institutes.

\section{Adhere to"school and enterprise cooperation" to cultivate teachers, "double -qualified "teachers' number and quality improved significantly}

"Colleges and universities is the palace to cultivate talents and only the talents can take on the task of cultivate talents" [6].For local colleges and universities cultivating applied talents, the number and quality of"double-qualified" teachers determines the quality of applied talents training. In the process of implementing "Five 'One' project", school timely launched "Three hundred projects" (100 teachers to enterprise,100 teachers for overseas study, introduced 100 high-level talents )to strengthen the construction of teaching staff (enterprise exercise under cadre of 100 teachers, 100 teachers overseas training, the introduction of high-level personnel, 100) and flexibly employed industry (enterprise) technical personnel system, greatly improved the number and structure of teaching faculty. Currently,school introduced 9 discipline, academic and technical leaders, sent 44 young leaders and teachers abroad ,sent more than 500 person-time teachers to enterprises for training and serve temporary positions and invited more than 380 person-time industry(enterprise) experts to take part-time jobs at school.There are 248 "double-qualified" teachers, accounting for $31.6 \%$.

Although "Five 'One' project" has made some achievements, we know it well that local college transitional development is a system project. It's a difficult task with a long way to go. Only by always adhering to the "the integrating of profession setting with local economic development, supporting of educational quality and benefit to local economic and social development, satisfaction of people to educational quality and level " as the important standard to measure the success or failure of the school education, preserving innovation can we constantly promote the birth of a new school.

\section{ACKNOWLEDGMENT}

Hunan Province 2015 Regular Institutions of Higher Education Teaching Reform Project(Xiang Jiao Tong[2015]291)-“The theory and practice research of transitional development in local colleges and universities--take Xiangnan University as example". Hunan Province 2012 Regular Institutions of Higher Education Teaching Reform Project(Xiang Jiao Tong ([2012]401 - 438)- "A study on the Information management major practice teaching reform and innovation based on the double characteristics of locality and school".

\section{REFERENCES}

[1] Kong Fanmin, Guo Shumin,Tang Xiaoheng.etc. The Road to Construction Applied University.Version 1[M].Beijing:Beijing Student Press,2006,47-50.

[2] Lenin.Lenin Selections: 2 Volume[M].Beijing: People Press, 1995,103.

[3] Mao Zedong.Mao Zedong Selections:3 Volume[M].Beijing: People Press, 1991,789.

[4] Shu Wen. Salary Ranking List of College Graduates in 5 years,average 7393RMB/month of Hunan University and Central South University [N].Changsha Evening,2014,06-18.

[5] Ma Tingqi.On teaching responsibility of college students[J].Higher Education Research,2008(5),24.

[6] Jiagn Xiao. "Study On the Educational Philosophy of American educators". Comparative Education Review, 1988,pp25.

[7] Wittgenstein, Edited by Wright Neiman etc, Translated by Xu Zhiqiang. "Culture and value- Wittgenstein's informal essay". Hangzhou: Zhejiang Literature and Art Publishing House, 2002,pp87

[8] Marx,Engels."Selected Works".Beijing: Beijing People's Publishing Agency,1995,pp341-342.

[9] Edgar Morin, translated by Chen YiZhuang. "Complexity theory and education”. Beijing: Peking University Press,2004,pp43.

[10 ]Yang Zhongkai, Liu Yongzhen. "From simplicity to complexity". System dialectics report,2002,pp47. 